\title{
COMPARISON OF NATURAL AND CHEMICAL COAGULANTS TO REMOVE TURBIDITY
}

*Nada Kamil Faraj ${ }^{*}$
Dr. Zaidun Naji Abudi ${ }^{2}$

1) M.Sc. Environment Engineering Department, Al-Mustansiriyah University, Baghdad, Iraq.

2) Asst. Prof. Dr., Environment Engineering Department, Al-Mustansiriyah University, Baghdad, Iraq.

\begin{abstract}
Turbidity is a common problem in river water that is usually treats through a processes coagulation and flocculation because it contains particles, colloids and plankton. The aim of this study is to find out the possibility of using natural coagulants the rice husk and $\mathrm{MO}$ in order to remove or reduce turbidity and compare the results with the chemical coagulants used in water treatment plants (alum). The experiment is conduct using a jar test. Four different operation parameters were studied (coagulant's dose $(0.05-1.5 \mathrm{~g})$, solution $\mathrm{pH}(2-12)$, practical size $(600,300$, and $150 \mu \mathrm{m})$, and mixing speed (40-240 $\mathrm{rpm})$. The raw water sample (turbid water) prepared in lab with 200 NTU. The results showed that the highest turbidity removal by rice husk and MO were $96.6 \%$ and $96.3 \%$, respectively, at the coagulation's dose of $0.5 \mathrm{~g} / \mathrm{L}$, $\mathrm{pH} 7$, particle size $300 \mu \mathrm{m}$, and a mixing speed of $120 \mathrm{rpm}$. While the alum efficiency was $97.0 \%$ at the coagulation's dose of $1 \mathrm{~g} / \mathrm{L}$, Ph 6 and a mixing speed of $120 \mathrm{rpm}$.
\end{abstract}

Keywords: Turbidity, natural coagulants, Coagulation, flocculation, rice husks, MO, Alum.

\section{Introduction}

Water is the main and important resource for human life and living organisms and is the mean of life; human life depends entirely on water. Therefore, lake water, steam water, marine and tourist areas water, groundwater, river water and other high-value water resources that must protected from pollution [1].
Water resources in Iraq constitute about 15\% of the total area in all its various forms, which are lakes, seas, rivers, etc. it is very necessary to preserve and maintain these resources for agricultural, industrial and domestic uses [2].

Water is use in many fields including industrial, agricultural and human uses. As a result of industrial development the world is witnessing increasing water demand by increasing the number of people and increasing the amount of pollutants that often end up in rivers and become a barrier without benefiting from them, sometimes the risk reaches the human exposure to danger and damage agriculture crops and the death of aquatic organisms.

Water resources in Iraq are affecting by many sources of pollution. That the water produced from the various uses (human, agricultural and industrial) drained to rivers and other water bodies is a major source of pollution to degrade the quality of watersheds.

Rivers are one of these resources that suffer from an environmental problem due to the excesses caused by Factory waste [3]. 
Turbidity is a measure of the impurities in the water that formed by the bodies suspended in the water. Turbidity can be causing by organic matter, silt, clay particles, and microorganisms.

Typically measured in NTUs Excessive turbidity in drinking water is not acceptable it may also be a cause for concern about health as it may provide food and shelter for pathogens [4].

The presence of turbidity at high levels in rivers poses a great risk to human health because pollutants such as bacteria and viruses become suspend or protected [5].

The suspended particles in the water can classify into two categories:

1- Biomaterials such as viruses, bacteria, and others Live and non-living organic matter [6].

2- Inorganic materials such as minerals and silt.

In many plants, changing water characteristics require the operator to adjust coagulant dosages at intervals to achieve optimal coagulation. Different dosages of coagulants are test using a jar test, which mimics the conditions found in the treatment plant. Jar test, is one of the simplified methods used to predict the amount and type of coagulant that give the agglomeration by dose, as well as treatment methods. The first step of the jar test involves adding coagulant to the source water and mixing the water rapidly to completely dissolve the coagulant in the water. Then the water is mixed slowly for a longer time, mimicking the flocculation basin conditions and allowing the forming flock particles to cluster together. Finally, the mixer is stop and the flock is allowed to settle out, as it would in the sedimentation basin [7].

When turbidity levels to an undesirable level is available upon request. This feature can prevent internal damage from occurring and ensure the optimum quality of purity. Water treatment systems to reduce turbidity levels are superior filter media and filtration systems.

These systems are the ideal solutions to reduce turbidity as they filter suspended particles that contribute to various degrees of turbidity. Palm scaling can be used to describe the fundamental difference between media systems and filtration. Media filter systems remove suspended solids from the water. While the filtration systems remove suspended solids it also filters out some bacteria and viruses.

Surface water plants in contrast tend to treat water with a high turbidity is susceptible to sudden changes in water quality.

Operators at these plants will perform jar tests frequently, especially after rains, to adjust the coagulant dosage and deal with the changing turbidity.

The coagulation is one of the most important processes for treating water, and it is essential in the treatment system, as it removes turbiditycausing substances such as (bacteria, clay particles, colloidal particles, and color) resulting from agricultural and industrial wastewater. The negative charge is present on the surface of suspended particles (small particles), which leads to repelling each other, thus remaining stuck in water at their small sizes[4] .

Coagulation/flocculation is the process of binding small particles in the water together into larger, heavier clumps which settle out relatively quickly. The larger particles are known as flock. Properly formed flock will settle out of water quickly in the sedimentation basin, removing the majority of the water turbidity [8].

Coagulation is being by adding coagulants such as alum Despite the effectiveness of alum and its low cost the use of alum in the coagulation 
process has many drawbacks for example during the process of treating sludge that can cause environmental problems [9-10] It can also cause many diseases, including Cancer and Alzheimer's [11].

In the past years agricultural wastes have been used as natural coagulants in the recycling process instead of chemicals and there have been many studies among which the researcher (Sanchez) in 2009 examined the use of material technology as a natural coagulant to treat wastewater from turbidity Where he got $100 \%$ high removal efficiency[12].The scientist Amen et.al. (2003) studied the fruit of the plant (Carob bean) the possibility of using it as an aid to coagulation with alum and obtained an efficiency of $100 \%$ [13].

Muyibi, et.ai.(2003) also studied the efficiency of (MO extract seed) as an aid in the process of coagulation with alum to remove its turbidity (0.9-2.7) NTU [14].

The search process was carried out on environmentally friendly natural coagulants and the conversion of unwanted agricultural wastes, which must be disposed of which are millions of kilograms produced annually into coagulants that are used in water treatment, and these materials are rice husks and MO [15-16].

Rice husks are a by-product of the rice milling process. Rice husks are produced large can be used economically in the water treatment process because they possess high chemical and mechanical sediment with their granular structure so they can be used as coagulants [17].

MO is one of the plants used as natural coagulants for water treatment, and it is very effective in removal. MO is a non-toxic plant [18]. The leaves of Moen are rich in calcium, vitamin C, iron and organic polymers [19].
In Developing countries, it is well known that MO plants are used as a natural source of soils'. $\mathrm{MO}$ analysis shows that these plants contain high acids such as glutamine, argentine and praline, The powdered of the MO has coagulating properties that have been used for various aspects of water treatment such as turbidity, alkalinity, total dissolved solids and hardness [20]. The objectives of the study were (1) to reduce the amount of turbidity using locally available natural coagulants. (2) To compare the results with the conventional chemical coagulant (alum).

\section{Material and Methods:}

\subsection{Materials}

Clay Kaolin, alum, $\mathrm{NaOH}(0.1 \mathrm{~N}), \mathrm{HCl}(0.1 \mathrm{~N})$, distilled water, chemicals source from scientific offices in Baghdad .Rice husks are from the farms of Najaf/Iraq. MO its Waste agricultural was obtained from Baghdad/Al-Mustansiriyah University, and College of Engineering.

\subsubsection{Rice husk}

Rice husks were washed to remove dirt and dust by tap water and then washed by distilled water to remove salts and then dried them by sunlight for 48 hours. After making sure that it was completely dried, they were turn it to powder by grinding them with a mill for 40 seconds until they became fine powder and sift with a sieve of diameter 600, 300 and $150 \mu \mathrm{m}$ and saved Crusted powder in a dry place (plastic cans) to be used in the experiment.

\subsubsection{Moringa Oleifera}

MO were washed to remove dirt and dust by tap water and then washed by distilled water to remove salts and then dried them by sunlight for 96 hours. After making sure that it was 
completely dried, they were turn it to powder by grinding them with a mill for 30 seconds until they became fine powder and sift with a sieve of diameter 600 ,300 and $150 \mu \mathrm{m}$ and Saved Crusted powder in a dry place (plastic cans) to be used in the experiment .

\subsubsection{Alum solution preparation}

The aqueous solution is prepared by dissolving $10 \mathrm{~g}$ of aluminum sulfate ( $\mathrm{Al} 2(\mathrm{SO} 4) 3.18 \mathrm{H} 2 \mathrm{O})$ in 1 liter of distilled water and shaking and mixing until it melts to generate $10 \%$ solution concentration, thus each $1 \mathrm{ml}$ of the aqueous solution gives $10 \mathrm{mg}$ of alum.

\subsubsection{Synthetic turbid water preparation}

$10 \mathrm{~g}$ of clay kaolin were dried in an oven at $100 \mathrm{C}$ for 6 hours. It was added to1 liter of distilled water and then stirred to melt at a speed of 20rpm for one hour and completing moisturizing kaolin was left for 24 hours and the suspension was obtained for the purpose of preparing samples contaminated with turbidity.

\subsubsection{Jar Test Operations}

One of the most traditional laboratory methods used for natural coagulation is the jar test, as all natural coagulation experiments have been used ,The device was used by preparing 200NTU 1 liter of processed turbidity water and placing it in the six beakers of the device. After that, the sample is mixing well before using the device and measuring the turbidity that represents the initial concentration (TA) measuring the turbidity after added the coagulants to the processed water.

the apparatus are operate using a high speed of up to 200rpm for 2 minutes using an agitator and after rapid mixing the slow mixing comes at a speed of 40rpm for 20 minutes the sample is left for precipitation for 30 minutes and after leveling it is withdrawn from a distance of up to $6 \mathrm{~cm}$ from the sample surface to measure the remaining turbidity and represents (TR) and after It calculates the percentage of removal

$\mathrm{T}=((\mathrm{TA}-\mathrm{TR}) / \mathrm{TA}) \times 100 \%$

To find the most favorable operation conditions, the coagulation dose was changed $(0.01-1.5) \mathrm{g} / \mathrm{L}$, solution $\mathrm{pH}$ (2-12), coagulants particle size (150, 300 , and 600) $\mu \mathrm{m}$, and mixing speed (40-240) rpm.

\section{Results and Discussion}

\subsection{Effect of the coagulant dose}

The study the effect of the coagulation dose on the turbidity removal process coagulants (alum, rice husks and MO) were used as primary coagulant in the treatment of river water at a manufactured turbidity of 200NTU and with a and with a wide range of doses ranging from (1.5$0.01) \mathrm{g} / \mathrm{L}$ and the highest removal rate was Rice and MO (95.47 and 94.7) respectively at a dose of (0.5) g/L.As for alum it was a high removal rate compared with the coagulants used (97.22) at $1 \mathrm{gm} / \mathrm{L}$. the examination were carry out using a jar examination.

Figure (1) we notice that the more coagulation dose increases the removal ratios increase. The reason for this is because the amount of proteins needed to bind all the particles scattered in the aqueous solution increases with increasing coagulation dose until we get the highest isolation ratios that are alum and they have been adopted as the optimal dose $(1 \mathrm{~g} / \mathrm{L})$ After the optimal dose the removal rate will decrease as a result The dose of coagulation more than optimal may itself contribute to the generation of turbidity in the aqueous solution [21]. 


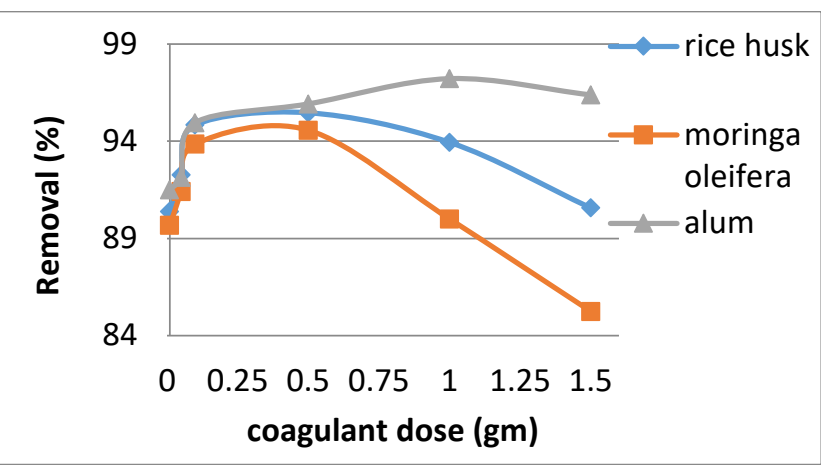

Figure 1.The effect of coagulant dose on turbidity removal at a PH (7), a sieve (300) $\mu \mathrm{m}$, a Mixing speed (200) rpm and a fixed turbidity of 200 NTU.

\subsection{Assess the pH effect}

To assess the $\mathrm{pH}$ effect another set of jar tests perform to remove turbidity. The $\mathrm{pH}$ of the water greatly affects the activity of the coagulants due to the active components of the coagulants used (code or role). To monitor the $\mathrm{pH}$ effect the tests were performed at values (2-12). The highest level of removal of natural coagulants (rice husks and MO) is (94.84), (95.89) were at $\mathrm{pH} 7$ without prior adjustment, as the activity of natural coagulants in the water becomes high at the $\mathrm{Ph} 7$ But when the $\mathrm{pH}$ more than 7 the removal rate is decrease because some types of natural coagulants are less attractive and as a result they become less attractive to ionic organic compounds. While using chemical coagulant (alumni), alum has the highest ratio (97) at $\mathrm{pH}$ 6.These results indicate that the extract of the natural coagulants used consists of both cationic and anionic coagulating components at lower $\mathrm{pH}$ values the anionic components of coagulant are responsible for turbidity removal. Likewise when the $\mathrm{pH}$ values rise the positive protein components are activate. However, poor coagulation activity noticed in neutral $\mathrm{pH}$ zone at values (2, 4, 10, and 12) as illustrated in Figure (2).Although conducting coagulation tests at extreme $\mathrm{pH}$ values may violate the guidelines of EPA; only higher $\mathrm{pH}$ values give excellent results in terms of coagulation activity [22]. The $\mathrm{pH}$ values of clarified water adjust by adding molar quantities of acid or base at the end of each coagulation test.

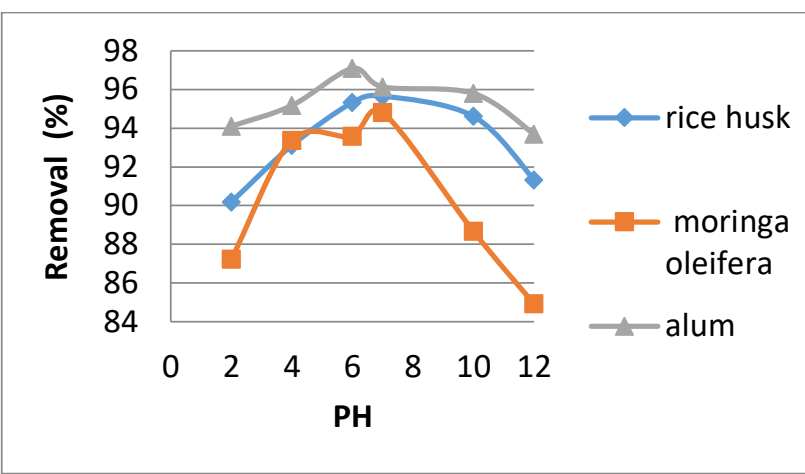

Figure 2.The effect of $\mathrm{PH}$ on removal turbidity at an optimum coagulation dose, sieve (300) $\mu \mathrm{m}$, speed (200) rpm and a fixed turbidity of 200 NTU.

\subsection{Effect of coagulant particle size}

The study of the effect of particle size of the coagulant used in the coagulation process is Important it provides valuable information on the expected performance of a particular coagulant. To study the effect of volume, different sieve sizes were used, which are $(600,300$ and 150 $\mu \mathrm{m})$. Figure (3) shows that the removal efficiency at (150) $\mu \mathrm{m}$ is low due to the low surface distance of the coagulated material. The highest removal rate was obtained with a size of (300) $\mu \mathrm{m}$, which is for rice husks $(96.12 \%)$ and MO $(96.38 \%)$ because the surface area between the particles is large. While when the size increased to $600 \mu \mathrm{m}$ the removal percentage was decrease and the reason for this is that the spatial distance of the coagulated material is large, granular and loose [23].

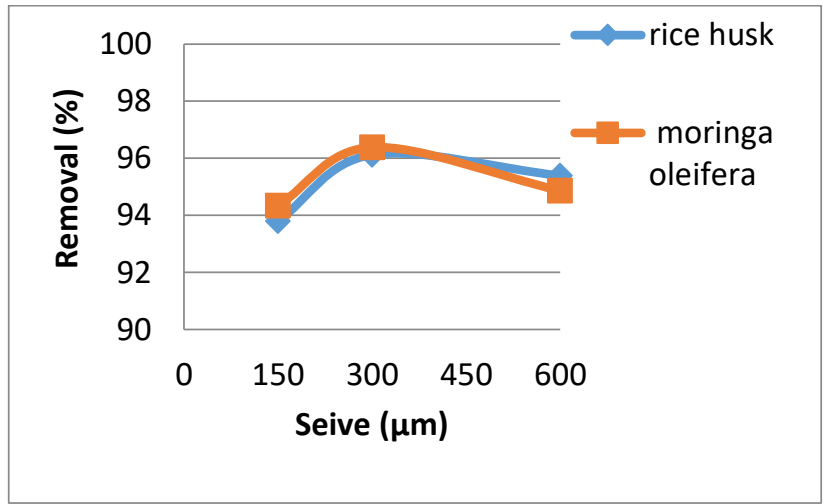

Figure 3.The effect of particle size on turbidity removal at an optimum coagulation dose, an optimum $\mathrm{pH}$, Mixing speed (200) rpm and a fixed turbidity of 200NTU. 


\subsection{Effect of mixing speed}

One of the important factors for achieving high flocculation efficiency during the coagulation process is the mixing effect of the mixing materials used [24]. Figure (4) shows that the faster the coagulant the higher the removal rate. The highest rates of coagulation removal (rice husks and MO) were 96.7and 96.3 respectively. Was achieved at (120) rpm. While the highest turbidity removal rate when using alum is $97 \%$ at speed (200) rpm, the higher the speed the more than $120 \mathrm{rpm}$, the less removal rate and the reason for this are the increased shear masses [25].

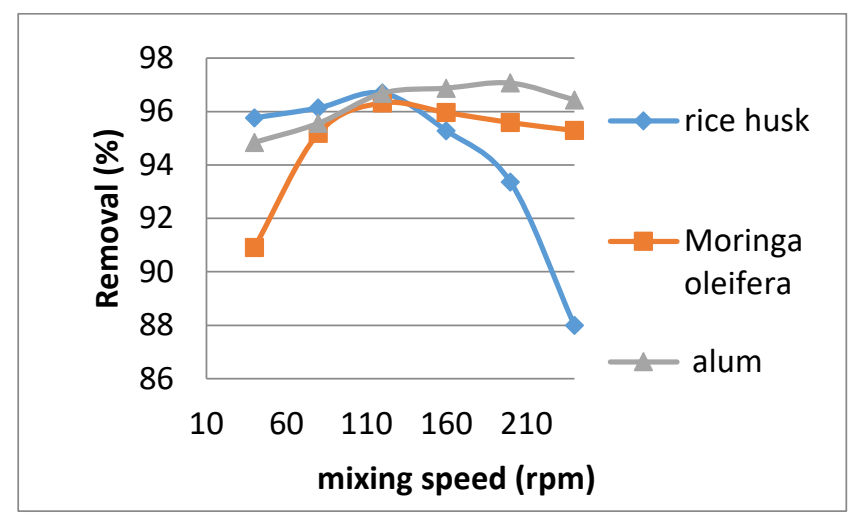

Figure 4.The effect of mixing speed on turbidity removal at an optimum coagulation dose, an optimum $\mathrm{pH}$, an optimum sieve and a fixed turbidity of 200NTU.

\section{Conclusions}

The purpose of this study is to investigate the ability of some natural coagulants (rice husks and MO) and compare the results with the conventional coagulants (alum) frequently used in the treatment plant. With natural coagulants used, however, natural coagulants are suitable for removing turbidity for several reasons, including

1. Aluminum sulfate (alum) achieved the best de-turbidity efficiency with an efficiency of (97\%), followed by rice husks efficiently (96.6\%), and then MO with an efficiency
(96.3\%),Through the results we conclude that the natural coagulant

2. Substances used in this experiment are appropriate for removing turbidity.

3. The possibility of producing natural coagulants locally.

4. It reduces sludge treatment costs and reduces the amount of waste generate Reducing sludge treatment costs.

\section{Acknowledgements}

I thank Al-Mustansiriyah University / College of Engineering for its help and support for this research.

\section{Conflict of interest}

There are not conflicts to declare.

$\begin{array}{ll}\text { Abbreviations } \\ \text { T } & \text { Turbidity } \\ \text { MO } & \text { Moringa Oleifera } \\ \text { TR } & \text { Remaining turbidity } \\ \text { TA } & \text { Initial turbidity }\end{array}$

\section{References}

1. Chauhan, et al. (2015). "Purification of drinking water with the application of natural extract". Journal of Global Biosciences, 4(1): $1861-1866$

2. Obais, A.A. (2012). "Assessment and Monitoring of Shaft Al_Hilla River with the middle Euphrates Region". Journal of Babylon University /Engineering sciences /No.(4)/Vol.(20).

3. .Jodi, et.ai. (2012)."The use of some plants in water purification". . Global Advanced Research Journal of Chemistry and Material Science, 1, 71-75. 
4. Ebeling, et.al. (2003) summer felt "Evaluation of chemical coagulation_/flocculation aids for the removal of suspended solids and phosphorus from intensive recalculating aquaculture effluent discharge", J. Aqua cultural Engineering 29, 23-42.

5. U.S. Environmental Protection Agency (EPA).Washington, D.C. (2005). "National Management Measures to Control Nonpoint Source Pollution from Urban Areas" .Chapters 7 and 8 Document No. EPA 841B-05-004 November.

6. EPA Guidance Manual Turbidity Provisions (EPA-GMTP). (1999)."Particles Contributing to Turbidity". Online: http"//www.epa.gov/OGWDW/mdbp/pdf/tur bidity/chap-08.pdf.

7. Oladoja , N.A. (2015). "Headway on natural polymeric coagulants in water and wastewater treatment operations".. J Wat Proc Eng 6: 174-192.

8. Ratshilivha, et al. (2014). "The variation in antimicrobial and antioxidant activities of acetone leaf extracts of 12 Moringa oleifera (Moringaceae) trees enables the selection of trees with additional uses". South African of Botany, 92, 59-64.

9. Bratby.J. (2006)."Coagulation and flocculation in water and waste water treatment". IWA publishing, Seattle, London. pp. $81-86$.

10. Camacho, et al. (2017). "The use of Moringa Olifer as natural coagulant in surface water treatment".chem.Eng.J.313, 226-237.

11. Ronda, et.al. (2000). "Relation between Aluminum concentrations in drinking water and Alzheimer's diseases an 8 year follows up study" .Am .J.Epidemiol .125, 59-66.

12. Sanchez and Beltran. (2009). "Municipal wastewater treatment by modified tannin flocculent agent". Desalination 249 pp353358.

13. Kharrufa, et.al. (2003). "Preliminary study for the efficiency of The Carob bean on the to coagulation process". Tikrit Jour. Of Eng. Sci., Vol.10.No.1.March.P (50-65).

14. Muyibi, et.al. (2003). "Treatment of surface water with Moringa Oleifera seed extract and alum- comparative study using a pilot scale water treatment plant". International Journal of Environmental Studies, Volume 60, Number 6, December, pp 617-626 (10).

15. Ciban, et al. (2009). "Removal of water turbidity by natural coagulants obtained from chestnut and acorn". Bioresour. Technol. $100,6639 \mathrm{e} 6643$.

16. Fatombi, et al (2013) " natural coagulant protein from copra (Cocas nucifera): isolation, characterization, and potential for water purification". Sep Purify Techno 2013,116: 35-40. doi:.1016/j.seppur.2013.05.015.

17. Swathe, et al. (2014). "Adsorption studies on tannery wastewater using rice husk". Scholars Journal of Engineering and Technology (SJET) vol.3, 253-257.

18. Ménage, et al. (2013). "Biosorption of cadmium from water using Moringa (Moringa oleifera Lam. seeds". Water Air Soil Pollute 224:1383.

19. Prasad, R. (2009). "Color removal from distillery spent wash through coagulation using Moringa oleifera seeds: use of optimum response surface methodology". J Hazard Mater 2009; 165 (1-3): 804-11. doi: 10.1016/j.jhazmat.10.068.

20. Arnoldson, et al. (2008) "Assessment of drinking water bark extracts of Moringa oleifera in reducing bacterial load in water". Into J Adv Res 4:124-130.

21. Okuda, et al. (2001)."Coagulation mechanism of salt solution-extracted active component in Moringa oleifera seeds". Water Res. 35 830e834.

22. United States Environmental Protection Agency. (2015)."Drinking water contaminants". Am. Child. Environ. 21e23.

23. Karts Kieran. (2004)".Adsorption dynamics and equilibrium studies of zinc (II) onto chitosan J". Chem. Sci., 116, No. 2, 119-127

24. Othman, et al. (2008)."Influence of the settle ability parameters for palm oil mill effluent pretreatment by using Moringa Oleifera seeds as an environmental friendly coagulant". Interference conference on Environment, Malaysia 1 -9. 
25. Ezek Ernest, et al. (2017)." Effects of pH, Dosage, Temperature and Mixing Speed on The Efficiency of Water Melon Seed in Removing the Turbidity and Color of At bong River, Awka-Ibom State, Nigeria".ternational Journal of Advanced Engineering, Management and Science (IJAEMS), Vol-3, Issue-5, p432. 